\title{
PERSEPSI KARYAWAN TERHADAP PENGGUNAAN TEKNOLOGI INFORMASI DALAM SISTEM INFORMASI AKUNTANSI (Studi Empiris di Rumah Sakit Permata Grup)
}

\author{
Henny $^{1}$, Iwan Koerniawan ${ }^{2}$ \\ 1,2Komputerisasi Akuntansi STEKOM Semarang \\ 1henny.fra@gmail.com, ${ }^{2}$ iwan@ @stekom.ac.id
}

\begin{abstract}
This study aims to determine employee perceptions about the use of information technology in accounting information systems at the Permata Group Hospital by using the theory of Technology Acceptance Model. The use of TAM model is based on the fact that so far TAM is a concept that is considered the best in explaining the behavior of the user of new information technology systems. The population in this study were all employees the Accounting and Finance at the Permata Group Hospital which includes Permata Bunda Hospital in Purwodadi and Permata Medika Hospital in Semarang. Sampling was conducted using population census, that is 32 people. These results prove the hypothesis is accepted 4 of total 5 proposed hypothesis Relationships proved significant : a) the effect of perceived ease of use (PEOU) on perceived usefulness (PU), b ) the effect of perceived ease of use (PEOU) of the attitude toward using (ATT), c ) the effect of perceived usefulness (PU) of the acceptance of information technology (ACIT), and d ) the effect of attitude toward using (ATT) on the acceptance of information technology (ACIT). This proves that the employees' perception of the use of information technology in accounting information systems based on information technology can be explained by the theory of Technology Acceptance Model (TAM) .
\end{abstract}

Keywords : Technology Acceptance Model (TAM), perceived ease of use (PEOU); perceived usefulness (PU), attitude toward using (ATT); acceptance of information technology ( ACIT ) .

A.

Pendahuluan

Dewasa ini semakin terlihat ketatnya persaingan di bidang pelayanan kesehatan. Perkembangan teknologi di era modernisasi seperti sekarang sangatlah cepat. Fred Davis pada tahun 1989 menyusun Technology Acceptance Model (TAM) untuk memahami perilaku penerimaan teknologi. Teori ini berasal dari sebuah teori induk (grand-theory) dari Fishbein \& Ajzen (1980) dengan nama Theory of Reasoned Action (TRA). Perkembangan teknologi sangat mendukung upayaupaya dalam peningkatan pelayanan kesehatan di rumah sakit.

Penelitian ini mengambil objek penelitian pada Permata Grup yang terdiri dari RS. Permata Bunda di Purwodadi dan Rumah Sakit Permata Medika di Semarang. Keduanya merupakan rumah sakit swasta kelas $\mathrm{C}$ dengan pemilik dan kebijakan umum yang sama. Penelitian dilakukan di Permata Grup karena Permata Grup merupakan rumah sakit yang telah menggunakan teknologi informasi dalam sistem informasi akuntansi yaitu dengan menggunakan program Sistem Biling RS. Dan peneliti berkeinginan untuk mengetahui apakah faktor-faktor yang mempengaruhi penggunaan sistem informasi akuntansi di Permata Grup yang berkaitan dengan teori Technology Acceptance Model. Maka penulis melakukan penelitian dengan judul Persepsi Karyawan Terhadap Penggunaan Teknologi Informasi Dalam Sistem Informasi Akuntansi (Studi Empiris di Rumah Sakit Permata Grup).

Penelitian ini bertujuan untuk mengetahui pengaruh persepsi kemudahan sistem/perceived ease of use (PEOU) terhadap persepsi kegunaan (perceived usefulness $(P U)$ dalam penggunaan sistem informasi akuntansi di Permata Grup, mengetahui pengaruh persepsi kegunaan/perceived usefulness (PU) terhadap sikap pengguna/attitude (ATT) dalam penggunaan sistem informasi akuntansi di Permata Grup, mengetahui pengaruh persepsi kemudahan sistem/perceived ease of use (PEOU) terhadap sikap pengguna/attitude (ATT) dalam penggunaan sistem informasi akuntansi di Permata Grup, mengetahui pengaruh persepsi kegunaan/perceived usefulness (PU) terhadap penerimaan TI (acceptance of IT) dalam penggunaan sistem informasi akuntansi di Permata Grup, dan untuk mengetahui pengaruh sikap pengguna/attitude (ATT) terhadap penerimaan TI (acceptance of IT) dalam penggunaan sistem informasi akuntansi di Permata Grup.

\section{B. Dasar Teori}

Penelitian ini menggunakan dasar teori dari Theory of Reasoned Action (TRA) yang pertama kali 
dicetuskan oleh Ajzen pada tahun 1980 (Jogiyanto, 2007). Dalam TRA ini, Ajzen (1980) menyatakan bahwa niat seseorang menentukan akan dilakukan atau tidak dilakukannya perilaku. Dan Theory of Planned Behavior (TPB) yang merupakan pengembangan lebih lanjut dari TRA. Ajzen (1988) menambahkan kontrol perilaku yang dipersepsi (perceived behavioral control). Penambahan ini untuk memahami keterbatasan yang dimiliki individu dalam rangka melakukan perilaku tertentu (Chau dan Hu, 2002). Dengan kata lain, dilakukan atau tidak dilakukannya suatu perilaku tidak hanya ditentukan oleh sikap dan norma subjektif semata, tetapi juga ditentukan oleh persepsi individu terhadap kontrol yang bersumber pada keyakinannya terhadap kontrol tersebut (control beliefs). Secara lebih lengkap Ajzen (2005) menambahkan faktor latar belakang individu ke dalam TPB. Kedua teori tersebut berkembang dan menjadi Theory Acceptance Model (TAM) yang menjelaskan hubungan antara keyakinan/beliefs (usefulness dan ease of use) dengan sikap/attitude, tujuanlintentions pemakai, serta penggunaan nyata dari sistem.

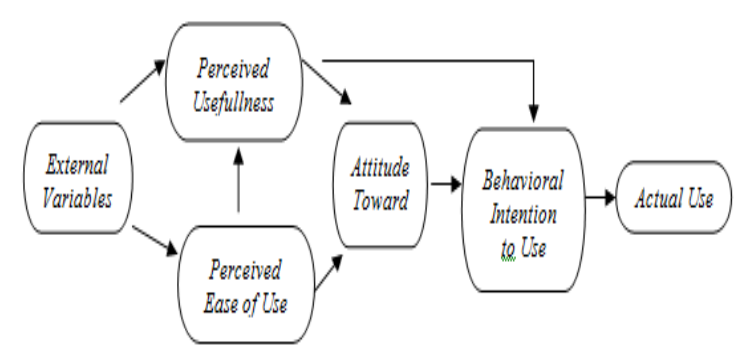

Gambar 1 Hubungan antar komponen dalam TAM Sumber : Davis, F.D. 1989

Hubungan antar komponen dalam TAM menunjukkan bahwa persepsi kemudahan penggunaan (Perceived Ease of Use) berpengaruh terhadap persepsi kegunaan penggunaan (Perceived Usefulness). Dan kedua persepsi tersebut berpengaruh pada sikap terhadap penggunaan (Attitude Toward Using). Sedangkan sikap terhadap penggunaan berpengaruh terhadap minat perilaku penggunaan (Behavioral Intention to Use). Selain itu, minat perilaku penggunaan juga dipengaruhi oleh persepsi kegunaan penggunaan. Dan minat perilaku penggunaan berpengaruh terhadap penggunaan nyata (Actual Use).

Penelitian ini merupakan replikasi dari penelitian Budi Santoso, Program Magister Akuntansi Universitas Sebelas Maret Surakarta (2010) yang menggunakan konsep teori Technology Acceptance
Model (TAM) dengan menggunakan variabel perceived ease of use (PEOU), perceived usefulness (PU), perceived enjoyment (PE), attitude toward using (ATT), dan acceptance of information technology (ACIT). Tetapi dalam penelitian ini tidak menggunakan variabel perceived enjoyment (PE) karena persepsi kenyamanan dapat dijelaskan dengan variabel perceived ease of use (PEOU) sehingga variabel-variabel yang digunakan pada penelitian ini lebih sesuai daripada penelitian terdahulu. Penelitian lain berkaitan dengan TAM pernah dilakukan oleh Stevanus Wisnu Wijaya (2006), Ratih Wijayanti, (2009), Fitriansyah Hambali, Armaini Akhirson, dan Ratih Wijayanti (2011), I Made Agus Ana Widiatmika dan Totok Dewayanto (2011), Dana Indra Sensuse (2012).

\section{Metode Penelitian}

Penelitian ini menggunakan metode survey dengan kuesioner, sedangkan analisis data menggunakan metode kuantitatif. Populasi dalam penelitian ini adalah Direktorat Keuangan Rumah Sakit Permata Bunda Purwodadi dan Rumah Sakit Permata Medika Semarang. Pengambilan sampel menggunakan metode Sensus sehingga jumlah sampel dalam penelitian ini adalah 32 orang. Peneliti menggunakan kuesioner yang ditujukan kepada manajer, kepala seksi, dan pelaksana bagian akuntansi dan keuangan RS. Permata Bunda Purwodadi dan RS. Permata Medika Semarang.

Pengukuran masing-masing variabel menggunakan skala Likert 1 sampai dengan 5 yang mempunyai arti sebagai berikut :

1 = Sangat Tidak Setuju (STT) $4=$ Setuju (S)

$2=$ Tidak Setuju (TS) $5=$ Sangat Setuju (SS)

3 = Tidak Pasti (TP)

Menggunakan model analisis Structural Equation Model (SEM). Variabel eksogennya adalah perceiveid easy of use. Sedangkan variabel endogennya adalah perceived usefulness, attitude toward using dan acceptance of IT. Sedangkan instrumen penelitian yang digunakan adalah observasi yaitu berupa pengamatan langsung dan kuesioner pada bulan Juni 2014. Teknik analisis yang digunakan adalah statistik deskriptif dan inferensia dan model empiris berbasis PLS dengan software SmartPLS.

\section{Hasil Penelitian Dan Pembahasan}

Responden dalam penelitian ini adalah karyawan/wati bagian keuangan pada Permata Grup. Pengiriman kuesioner pada tanggal 18 Juni 2014, dan diambil kembali pada tanggal 25 Juni 2014. Total 
kuesioner yang dikirim sebanyak 32 kuesioner. Kuesioner yang kembali untuk diolah sebanyak 32 kuesioner (100\%).

Adapun kecenderungan responden dalam menjawab pertanyaan adalah Perceived Ease of Use/PEOU yang berarti bahwa teknologi informasi yaitu sistem billing yang digunakan pada sistem informasi akuntansi mudah digunakan, mudah dipahami, dan membantu koordinasi dengan bagian lain untuk menghasilkan laporan keuangan yang dibutuhkan, tetapi network program sistem billing sering mengalami gangguan. Dan banyak responden yang setuju bahwa sistem billing mampu menyediakan kuitansi dan rincian biaya perawatan pasien, mampu menyediakan informasi keuangan yang akurat pada saat dibutuhkan, mempunyai pengaturan otorisasi/kewenangan penggunaan program, mampu menyediakan sistem keamanan backup data, dan mampu menyediakan data yang mendukung dalam pengambilan keputusan manajerial (Perceived Usefulness/PU). Banyak responden yang setuju bahwa sistem billing membuat cepat penyelesaian pekerjaan, meningkatkan motivasi untuk berkoordinasi dengan bagian lain, dan banyak karyawan/wati berpendapat pekerjaan menjadi menyenangkan. Hal tersebut merupakan Attitude Toward Using (Sikap terhadap penggunaan) di dalam Theory Acceptance Model. Dalam kaitannya dengan penerimaan teknologi (Acceptance of IT/ACIT), sebagian responden setuju bahwa semua data keuangan telah diolah oleh sistem billing RS, tetapi tergantung kepada tenaga listrik, terutama gangguan pada sistem billing apabila terjadi pemadaman listrik.

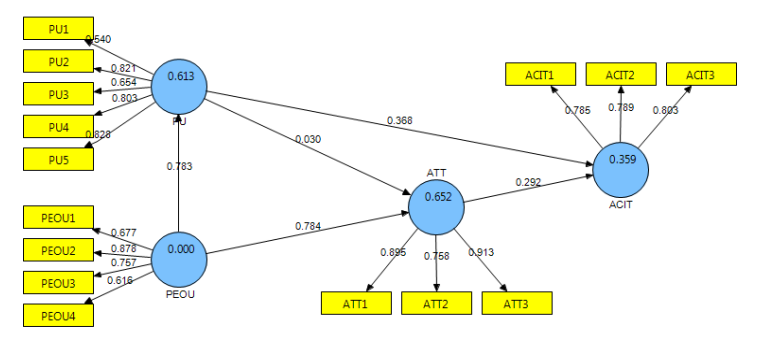

\section{Gambar 2 Hasil Uji Convergent Validity}

Sumber: Output SmartPLS

Hasil pengujian convergent validity dengan program SmartPLS Versi 2.0 dapat dilihat pada Gambar 2 yang menunjukkan bahwa semua nilai loading factor $(\lambda)$ dari indikator variabel penelitian hasil estimasi lebih besar dari 0,5. Hal ini menunjukkan bahwa indikatorindikator tersebut valid semua sehingga tidak ada indikator yang gugur atau dikeluarkan dari model.
Dengan demikian maka data dalam penelitian ini dapat digunakan untuk analisis selanjutnya.

Discriminant validity atau uji daya beda adalah pengujian sebuah indikator betul-betul menguji variabel yang dibentuknya, bukan variabel yang lain. Discriminant validity dapat dilihat dengan membandingkan square root of average extracted (AVE) tiap variabel dengan variabel lainnya. Evaluasi model pengukuran dengan square root of average variance extracted adalah membandingkan nilai akar AVE dengan korelasi antar konstruk. Jika nilai akar AVE lebih tinggi daripada nilai korelasi di antara konstrak, maka discriminant validity yang baik tercapai (Ghozali, 2006: 41 dan Fornell \& Lacker, dalam Yamin \& Kurniawan, 2009:223). Selain itu, nilai AVE lebih besar dari 0,5 sangat direkomendasikan (Tasha Hoover, dalam Yamin \& Kurniawan, 2009:233). Hasil pengujian discriminant validity dapat dilihat pada Tabel 1.

Tabel 1

Nilai Korelasi Antar Variabel, AVE, AKAR AVE

\begin{tabular}{|c|c|c|c|c|c|}
\hline & ACIT & ATT & PEOU & PU & $\begin{array}{c}\text { RATA- } \\
\text { RATA }\end{array}$ \\
\hline ACIT & 1 & & & & \\
\hline ATT & 0.528732 & 1 & & & \\
\hline PEOU & 0.46775 & 0.807132 & 1 & & \\
\hline PU & 0.555582 & 0.643406 & 0.782691 & 1 & 0.630882 \\
\hline AVE & 0.62776 & 0.736208 & 0.545588 & 0.544651 & 0.613552 \\
\hline AKAR AVE & 0.792313 & 0.858026 & 0.738639 & 0.738005 & 0.781746 \\
\hline
\end{tabular}

Sumber: Output SmartPLS

Tabel 2

Nilai Composite Reliability Tiap Variabel

\begin{tabular}{|c|c|}
\hline & Composite Reliability \\
\hline ACIT & 0.834952 \\
\hline ATT & 0.892682 \\
\hline PEOU & 0.825106 \\
\hline PU & 0.853755 \\
\hline
\end{tabular}

Sumber : Output SmartPLS

Hasil Composite Reliability untuk variabel Perceived Ease of Use (PEOU), Perceived Usefulness (PU), Attitude Toward Using (ATT), Acceptance of IT (ACIT) menunjukkan nilai yang memuaskan yaitu semuanya di atas 0.700. Dengan demikian dapat diintrepretasikan bahwa alat ukur atau kuesioner yang digunakan adalah reliabel atau konsisten. 
Sedangkan Gambar 3 dan Tabel 3 menunjukkan pengujian hipotesa mengenai kausalitas yang dikembangkan dalam inner model). Koefisien jalur Perceived Ease Of Use (PEOU) ke Perceived Usefulness (PU) sebesar 0.783 (bertanda positif) berarti bahwa setiap peningkatan PEOU sebesar 1 satuan maka akan semakin meningkatkan PU sebesar 0.783 satuan. Koefisien jalur Perceived Ease Of Use (PEOU) ke Attitude Toward Using (ATT) sebesar 0.784 (bertanda positif) berarti bahwa setiap peningkatan Perceived Ease Of Use (PEOU) sebesar 1 satuan maka akan semakin meningkatkan Attitude Toward Using (ATT) sebesar 0.784 satuan. Koefisien jalur Perceived Usefulness (PU) ke Attitude Toward Using (ATT) sebesar 0.030 (bertanda positif) berarti bahwa setiap peningkatan Perceived Usefulness (PU) sebesar 1 satuan maka akan meningkatkan Attitude Toward Using(ATT) sebesar 0.030 satuan. Koefisien jalur variabel Perceived Usefulness (PU) ke Acceptance of IT (ACIT) sebesar 0.368 (bertanda positif) berarti bahwa setiap peningkatan Perceived Usefulness (PU) sebesar 1 satuan akan meningkatkan Acceptance of IT (ACIT) sebesar 0.368. Dan koefisien jalur Attitude Toward Using (ATT) ke Acceptance of IT (ACIT) sebesar 0.292 (bertanda positif) ke berarti bahwa setiap peningkatan Attitude Toward Using (ATT) sebesar 1 satuan akan meningkatkan Acceptance of IT (ACIT) sebesar 0.292 satuan.

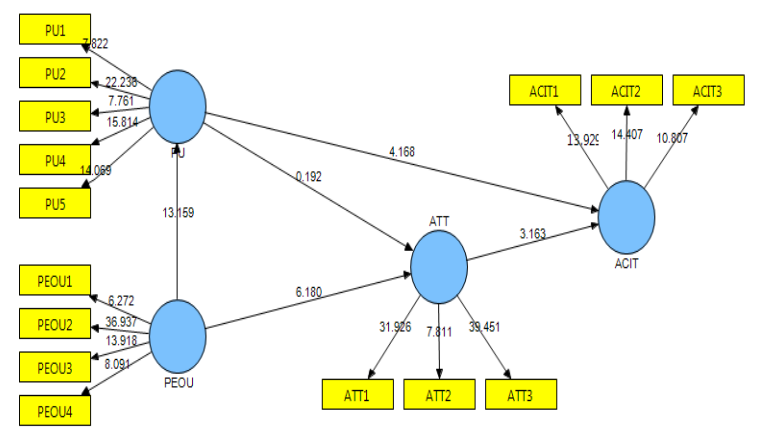

Gambar 3 Hasil Perhitungan Inner Model

TABEL 3

Path Coefficient dan Nilai Statistik Antar Variabel Path Coefficient (MEAN, STDEV, T-VALUES)

\begin{tabular}{|l|c|c|c|c|c|}
\hline & Original Sample & $\begin{array}{c}\text { Sample } \\
\text { Mean }\end{array}$ & $\begin{array}{c}\text { Standard } \\
\text { Deviation }\end{array}$ & Standard Error & T Statistics \\
\hline ATT $\rightarrow$ ACIT & 0.292251 & 0.297627 & 0.092230 & 0.092230 & 3.168707 \\
\hline PEOU $\rightarrow$ ATT & 0.783550 & 0.781814 & 0.110008 & 0.110008 & 7.122655 \\
\hline PEOU $\rightarrow$ PU & 0.782691 & 0.780346 & 0.055264 & 0.055264 & 14.162664 \\
\hline PU $\rightarrow$ ACIT & 0.367547 & 0.369134 & 0.095238 & 0.095238 & 3.859243 \\
\hline PU $\rightarrow$ ATT & 0.030129 & 0.030216 & 0.137830 & 0.137830 & 0.218595 \\
\hline
\end{tabular}

Sumber: Output SmartPLS, Tahun 2014.
Tabel 4 menunjukkan Nilai $R$-square dari variabel Perceived Usefulness (PU) adalah 0,613 yang berarti $61.30 \%$ variabel Perceived Usefulness (PU) dapat dijelaskan oleh Perceived Ease of Use (PEOU). Nilai $R$-square dari variabel Attitude Toward Using (ATT) adalah 0,652 yang berarti $65.20 \%$ variabel Attitude Toward Using (ATT) dapat dijelaskan oleh variabel Perceived Ease of Use (PEOU). Dan nilai $R$ square dari variabel Acceptance of IT (ACIT) adalah 0.359 yang berarti $35.90 \%$ variabel ACIT dapat dijelaskan oleh variabel Perceived Ease of Use (PEOU).

Tabel 4

Nilai R-Square Untuk Variabel Endogen

\begin{tabular}{|c|c|}
\hline & R Square \\
\hline PEOU & \\
\hline PU & 0.612605 \\
\hline ATT & 0.651814 \\
\hline ACIT & 0.358725 \\
\hline
\end{tabular}

Sumber: Output SmartPLS

\section{E. Kesimpulan}

Berdasarkan hasil analisis data penelitian menunjukkan bahwa kemudahaan penggunaan/ Perceived Ease of Use (PEOU) mempunyai hubungan yang positif terhadap persepsi kegunaan/Perceived Usefulness (PU), yang ditunjukkan dengan kemudahan penggunaan sistem billing rumah sakit yang sangat mendukung dalam menghasilkan laporan keuangan yang akan digunakan dalam pengambilan keputusan manajemen. Dan kemudahan penggunaan/Perceived Ease Of Use (PEOU) juga mempunyai hubungan yang positif terhadap sikap terhadap penggunaan/Attitude Toward Using (ATT) sistem billing rumah sakit karena rata-rata karyawan rumah sakit merasa nyaman menggunakan sistem billing tersebut. Tetapi persepsi terhadal kegunaan/Perceived Usefulness (PU) tidak mempunyai hubungan terhadap sikap terhadap penggunaan/Attitude Toward Using (ATT) karena meskipun sistem billing tersebut berguna, masih ada beberapa hal yang menghambat pekerjaan yaitu masih terjadi gangguan dalam penggunaan sistem billing apabila listrik padam dan program yang kadangkala mengalami gangguan dalam penggunaan operasional rumah sakit melayani pasien/keluarga pasien. Meskipun rumah sakit sudah mempunyai sistem pemeliharaan apabila terjadi pemadaman listrik, dengan menggunakan mesin genset tetapi gangguan terhadap data sistem billing masih sering 
terjadi,. Gangguan listrik menyebabkan program menjadi lambat dan kadang mengacaukan data. Untuk mengatasi hal tersebut, sistem billing menggunakan sistem untuk merapikan data yang disebut dengan Data Reindex. Dan persepsi kegunaan/Perceived Usefulness (PU) mempunyai hubungan positif terhadap Acceptance of IT (ACIT) karena dengan memandang kegunaan sistem billing tersebut dalam operasional rumah sakit dan dalam pengambilan keputusan manajemen, menimbulkan sikap penerimaan untuk menggunakannya. Sedangkan sikap terhadap penggunaan/Attitude Toward Using (ATT) mempunyai hubungan positif terhadap Acceptance of IT (ACIT) yaitu rasa nyaman menggunakan sistem billing dalam kegiatan operasional rumah sakit melayani pasien/keluarga pasien sehari-hari menyebabkan penggunaan sistem billing tersebut dapat diterima dalam operasional rumah sakit di lingkungan Permata Grup. Sehingga penelitian ini berkesimpulan bahwa sistem billing merupakan sistem yang paling sesuai untuk sistem informasi akuntansi di Permata Grup.

\section{DAFTAR PUSTAKA}

Ajzen, I., dan Fishbein, M., 1980, Understanding Attitudes and Predicting Social Behavior, PrenticeHall, Englewood Scliffs, NJ.

Ajzen, I., 1988, Attitudes, Personality, dan Behavior, Dorsey Press, Chicago.

Ajzen, I. (2005), Attitudes, Personality and Behavior, (2nd edition), Berkshire, UK: Open University PressMcGraw Hill Educationu

Budi Santoso, 2010, Pengaruh Perceived Usefulness, Perceived Ease of Use, dan Perceived Enjoyment terhadap Penerimaan Teknologi Informasi (Studi Empiris di Kabupaten Sragen), Tesis Program Pasca Sarjana Akuntansi Universitas Sebelas Maret Surakarta

Chau, Patrick Y.K dan Hu, Paul J (2002), Examining a Model of Information Technology Acceptance by Individual Proffessionals, An Exploratory Study (electronic version), Journal of Management Information System,18 (4), 191 - 229
Davis, F.D, 1989. Perceived Usefulness, Perceived Ease of Use and User Accept-ance of Information Technology, MIS Quarterly.

Fitriansyah Hambali, Armaini Akhirson, Ratih Wijayanti, 2011, Analisis Technology Acceptance Model (TAM) terhadap Faktor-Faktor yang Mempengaruhi Penerimaan Nasabah terhadap Layanan Internet Banking (Studi Empiris terhadap Nasabah Bank di Depok), Jurnal Proceeding PESAT, Vol. 4, Oktober

I Made Agus Ana Widiatmika, Dana Indra Sensuse, 2012, Pengembangan Model Penerimaan Teknologi Internet Oleh Pelajar dengan Menggunakan Konsep Technology Acceptance Model (TAM), Jurnal Sistem Informasi MTI-UI, Volume 4, No.2

Jogiyanto, 2007, Sistem Informasi Keperilakuan, Andi Offset Yogyakarta

Ratih Wijayanti, 2009, Analisis Technology Acceptance Model (TAM) Terhadap

Faktor-Faktor Yang Mempengaruhi Penerimaan Nasabah Terhadap Laya- nan Internet Banking (Studi Empiris Terhadap Nasabah Bank Di Depok), Fakultas Ekonomi, Jurusan Akuntansi Universitas Gunadarma

Stevanus Wisnu Wijaya, 2006, Kajian Teoritis Technology Acceptance Model Sebagai Model Pendekatan untuk Menentukan Strategi Mendorong Kemauan Pengguna dalam Menggunakan Teknologi Informasi dan Komunikasi, Jurnal Teknik Informatika Universitas Sanata Dharma Yogyakarta

Totok Dewayanto, 2011, Analisis Penerimaan Komputer Mikro dengan Menggu-nakan Technology Acceptance Model (TAM) pada Kantor Akuntan Publik (KAP) di Jawa Tengah, Jurnal STIE Semarang, Volume 3, No.2, Juni 


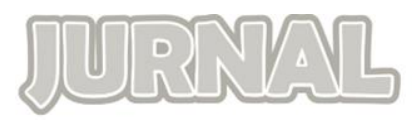

TEKNOLOGI INFORMASI DAN KOMUNIKASI 